\title{
Kritik Sosial Dalam Naskah Drama Bunga Rumah Makan Karya Utuy Tatang Sontani
}

\author{
Risky Ayu Safitri ${ }^{\text {* }}$ \\ ${ }^{1}$ Universitas Muhammadiyah Jakarta, \\ Jakarta Selatan, DKI Jakarta, Indonesia \\ *email: Rizkyas128@gmail.com
}

Received: 20 Juli 2020

Accepted: 30 September 2020

Published: 30 September 2020

doi: $10.22236 /$ imajeri.v3i1.5295

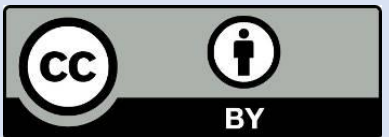

C 2020 Oleh authors. Lisensi Imajeri: Jurnal Pendidikan Bahasa dan Sastra Indonesia, Uhamka, Jakarta. Artikel ini bersifat open access yang didistribusikan di bawah syarat dan ketentuan Creative Commons Attribution (CC-BY) license.

(http://creativecommons.org/licenses/by/4.0/).

\section{Abstrak}

Drama hadir berdasarkan refleksi penulis terhadap realitas yang dihadapinya. Oleh karena itu drama berisi beragam aspek kehidupan manusia termasuk di dalamnya adalah kritik sosial. Penelitian ini bertujuan untuk mengetahui berbagai bentuk kritik sosial dalam naskah drama Bunga Rumah makan. Penelitian ini menggunakan metode deskriptif. Metode deskriptif adalah pendekatan penelitian yang sumber datanya berupa kata-kata. Objek yang akan diteliti adalah naskah drama Rumah Bunga Makan karya Utuy Tatang Sontani dengan menggunakan pendekatan sosiologi sastra. Hasil penelitian sosiologi sastra pada naskah drama Bunga Rumah Makan karya Utuy Tatang Sontani memaparkan secara jelas kondisi masyarakat mengenai berbagai macam permasalahan dalam kehidupan sosial.

Kata kunci: Sosiologisastra; Drama; Realisme.

\section{Abstract}

Drama comes based on the writer's reflection on the reality it faces. Therefore, drama contains various aspects of human life, including social criticism. This study aims to determine the various forms of social criticism in the drama script Bunga Rumah Makan. This research uses a descriptive method. Descriptive method is a research approach whose data source is in the form of words. . The object to be researched is the drama script Rumah Bunga Makan by Utuy Tatang Sontani using the sociology of literature approach. The results of the sociology of literature research on the drama script Bunga Rumah Makan by Utuy Tatang Sontani clearly explain the condition of society regarding various kinds of problems in social life.

Keywords: Sociological literature; Drama; Realism.

\section{PENDAHULUAN}

Sastra adalah karya imajinatif bermedia yang nilai estetikanya bernilai dominan. Melalui karya sastra, seorang pengarang bermaksud menyampaikan informasi, gambaran, atau pesan tertentu kepada pembaca. Sesuatu yang disampaikan itu biasanya merupakan gagasan tentang kehidupa yang ada di sekitar pengarang (Hikmat, Solihati, \& Hidayatullah, 2016; Lestari, 2020; Suwondo, 2011). 
Karya sastra merupakan wujud dari hasil pemikiran manusia. Selain itu, karya sastra juga mengandung dimensi-dimensi makna tambahan yang beroperasi dalam sebuah karya. Karya sastra diciptakan untuk dibaca, dinikmati, serta diambil nilai-nilai yang terkandung di dalamnya. Untuk lebih memahami suatu karya sastra, seorang penikmat sastra perlu mengapresiasi karya sastra tersebut agar lebih mendalami apa yang ingin disampaikan oleh pengarang (Wellek \& Warren, 1990). Karya sastra pada dasarnya merupakan ketaksadaran sebagai ketaksadaran transindividual. Karya sastra diciptakan pengarang atau sastrawan untuk dinikmati, dipahami, dan dimanfaatkan oleh masyarakat dalam kehidupan (Puspitasari, Hidayatullah, \& Jupri, 2019).

Salah satu jenis karya sastra adalah drama. Drama berarti perbuatan, tindakan. Berasal dari bahasa Yunani "draomai" yang berarti berbuat, berlaku, bertindak dan sebagainya. Drama merupakan tiruan kehidupan manusia yang diproyeksikan di atas pentas. Drama adalah kesenian yang melukiskan sifat manusia dengan gerak (Hidayat, 2015; Ibrohim, Turahmat, \& Wardani, 2018). Ibarat sebuah film, hidup adalah sebuah panggung sandiwara yang mana semua orang bisa berpura-pura menjadi siapa saja ketika di panggung. Namun sebelum mencapai proses pementasan drama, naskah drama menjadi yang paling pertama dipersiapkan. Naskah drama adalah salah satu genre karya sastra yang sejajar dengan prosa dan puisi. Perbedaan naskah drama dengan prosa dan puisi, naskah drama berbentuk dialog yang berdasarkan atas konflik batin dan kemungkinan akan dipentaskan (Hikmat et al., 2016). Naskah drama dapat diartikan suatu karangan atau cerita yang berupa tindakan atau perbuatan yang masih berbentuk teks atau tulisan yang belum diterbitkan (pentaskan). Yang akan diteliti dalam penelitian ini adalah naskah drama. Jadi dapat disimpulkan bahwa karya sastra lahir dari latar belakang dan dorongan dasar manusia untuk mengungkapkan eksistensi dirinya.

Sebuah karya sastra dipersepsikan sebagai ungkapan nyata kehidupan dan konteks penyajiannya, disusun secara terstruktur, menarik, serta menggunakan media bahasa berupa teks yang disusun melalui pengalaman dan pengetahuan secara potensial memiliki berbagai macam bentuk representasi kehidupan. Maka penelitian ini menggunakan metode penelitian Sosiologi Sastra. sosiologi sastra secara definitif merupakan aktivitas pemahaman dalam rangka mengungkapkan aspek-aspek kemasyarakatan yang terkandung dalam karya (Bahtiar, 2017). Dengan demikian karya tersebut merupakan bentuk atau media yang digunakan pengarang dalam menyampaikan gagasannya tentang kenyataan sosial yang terdapat dalam naskah drama.

Dalam hal ini penulis menggunakan naskah drama sebgai objek penelitian agar mempermudah proses penelitian tersebut. Naskah dapat dihasilkan dalam bentuk olahan asli atau adaptasi penulisan yang sudah ada seperti hasil sastra. Komponen-komponen utama dalam naskah drama terdiri dari aksi dan dialog. Aksi merujuk kepada "apa yang kita lihat", dan dialog merujuk kepada "apa yang 
dituturkan oleh tokoh". Tokoh-tokoh dalam naskah drama juga dapat diperkenalkan dalam bentuk visual di awal cerita.

Pemilihan naskah drama "Bunga Rumah Makan" didasari oleh beberapa faktor, yaitu penulis naskah adalah Utuy Tatang Sontani yang merupakan salah satu penulis naskah drama yang karya-karyanya sejak awal selalu mencerminkan kecenderungan pikiran-pikiran yang sangat rasional, menolak kekolotan, dan menentang idealisme yang tidak realistis, tetapi ia juga dikenal sebagai penulis yang humanis. Naskah drama "Bunga Rumah Makan" menceritakan sosok Ani yang bekerja sebagai pelayan atau pembantu rumah tangga di Rumah Makan Sambara milik Sudarma. Karnaen, keponakan Sudarma, menaruh hati pada Ani. Meskipun demikian, cintanya bertepuk sebelah tangan atau selalu ditolak. Penolakan yang dilakukan secara terus-menerus membuat Karnaen mencari cara untuk mencuri hati Ani.

Cinta Karnaen tiba-tiba harus kandas karena Ani justru mencintai seorang kapten tentara bernama Suherman. Namun, sikap Suherman yang berubah menjadi arogan di penghujung cerita justru menyebabkan Ani berpaling. Perempuan yatim piatu tersebut justru memilih bersama Iskandar, seorang gelandangan yang tidak punya pekerjaan, tetapi ia mempunyai kejujuran dan kebenaran dalam setiap tindakannya. Ani, seorang pelayan sekaligus "bunga" dari sebuah rumah makan memilih untuk meninggalkan pekerjaannya. Hal itu dilakukan demi sebuah cinta dan kejujuran bersama Iskandar.

Berdasarkan hal tersebut maka penelitian ini sangat menarik. Di sisi lain, penelitian yang mengkaji kritik sosial sudah dilakukan pada naskah drama (Anwar \& Syam, 2018; Mulyaningsih, 2017; Solihat, 2017). Namun dari penelitian tersebut belum ada yang mengkaji naskah dari Utuy Tatang Sontani. Selain itu, naskah ini juga sudah diteliti (Suprabowo \& Wiradharma, 2018; Zain, 2020), namun kedua penelitian itu tidak membahas tentang kritik sosial. Oleh karena itu, penelitian ini penting untuk menjawab pertanyaan bagaimana kritik sosial yang terdapat di dalam naskah drama Bunga Rumah Makan karya Utuy Tatang Sontani.

\section{METODE}

Salah satu jalan untuk menikmati karya sastra adalah melalui pengkajian atau penelitian. Metode penelitian merupakan cara untuk menganalisis sesuatu berkaitan dengan teknik kerja penelitian.Penelitian ini menggunakan metode deskriptif. Metode deskriptif adalah pendekatan penelitian yang sumber datanya berupa kata-kata. Metode deskriptif ini bertujuan memaparkan hasil temuan pada proses penelitian berdasarkan tujuan penelitian (Sugiyono, 2018).

Objek yang diteliti adalah naskah drama Bunga Rumah Makan karya Utuy Tatang Sontani dengan menggunakan pendekatan sosiologi sastra. Penelitian ini bertujuan untuk mengungkap representasi sosial dalam naskah drama tersebut. Teknik pengumpulan data dilaksanakan melalui beberaa tahap, yaitu: (1) menentukan objek penelitian dan fokus penelitian, (2) membaca dan memahami objek penelitian, (3) mencari pendekatan dan toeri yang cocok dianalisis dalam 
objek penelitian, (4) mengidentifikasi objek penelitian melalui pendekatan dan teori yang sudah ditetapkan, (5) menganalisis objek penelitian, (6) memasukan hasil analisis.

\section{HASIL DAN PEMBAHASAN}

Berdasarkan penelitian yang telah dilakukan terdapat permasalahan dalam kehidupan sosial dalam naskah drama Bunga Rumah Makan karya Utuy Tatang Sontani, dengan rincian sebagai berikut:

\section{Masalah Perbedaan Status Sosial}

Perbedaan status sosial antara si kaya dan si miskin sangat terlihat dalam penggalan drama "Bunga Rumah Makan". Dalam drama tersebut dikisahkan Sudarma merupakan orang dari keluarga mapan secara ekonomi. Sebagai orang mapan dalam ekonomi, Sudarma bersikap dan bertindak leluasa. Tindakan tersebut seperti yang dilakukan Sudarma kepada Pengemis.

SUDARMA : (masukmenjinjing tas, melihat kepadapengemis). Mengapa kau ada di sini? Ayo keluar!(kepadaAni). Mengapa dia dibiarkan masuk, An?

ANI

: Hendak saya beri uang.

SUDARMA : Tak perlu. Pemalas biar mati kelaparan. Toh dia datang hanya mengotorkan tempat saja.

ANI : (melemparuangkepadapengemis). Nih! Lekas pergi.

PENGEMIS : Terima kasih nona, moga-moga nona panjang umur.

SUDARMA : Ayo pergi. Jangan kau mendongeng pula. Lekas dan jangan datang lagi disini!

PENGEMIS : (pergikeluardengankakipincang).

SUDARMA : Lain kali orang begitu usir saja, An. Jangan rumah makan kita dikotorinya (dengan suara lain). Tak ada yang menanyakan aku?

Dari kutipan dialog diatas, Pengarang mencoba menciptakan karya sastra tersebut dengan menyadur kehidupan nyata yang dituangkan dalam suatu karya sastra berbentuk drama. Pengemis yang ada saat ini jumlahnya mungkin lebih banyak daripada dahulu. Pengemis dianggap sebagai manusia yang tidak mau berusaha dalam mencari nafkah. Mereka hanya menadahkan tangan mengharap belas kasihan orang lain. Sementara si kaya, mereka leluasa melakukan apa pun. Tidak sedikit pula orang kaya yang memedulikan pengemis yang meminta uluran tangan. pengemis mendapat hinaan bahkan cemoohan dari Sudarma yang kaya. Dengan demikian, sangatlah jelas bahwa status sosial memang dapat membedakan sikap dan harga diri seseorang. Orang kaya bisa melakukan apa pun, sedangkan orang miskin selalu ditindas. 


\section{Kejahatan}

Kejahatan atau kriminalitas tumbuh karena adanya berbagai ketimpangan sosial, yaitu adanya gejala-gejala kemasyarakatan, seperti krisis ekonomi, adanya keinginan- keinginan yang tidak tersalur, tekanan-tekanan mental, dendam, dan sebagainya. Dengan pengertian lain yang lebih luas, kejahatan timbul karena adanya perubahan masyarakat dan kebudayaan yang teramat dinamis dan cepat. Kejahatan tidak hanya disebabkan oleh disorganisasi sosial dan ekonomi, tetapi juga disebabkan oleh hubungan antara-antara variasi-variasi keburukan mental (kejahatan) dengan variasi-variasi organisasi sosial (Syani, 2007).

$\begin{array}{ll}\text { ANI } & : \text { (tampil dari belakang). Hei! Engkau mau mencuri ya! } \\ \text { PENGEMIS } & : \text { (cepat menarik tangan, menundukkan kepala) } \\ \text { ANI } & : \text { Hampir, tiap engkau datang disini, engkau kuberi uang. Tak } \\ & \text { sangka, kalau sekarang engkau berani - berani datang di } \\ & \text { sini dengan maksud mencuri. }\end{array}$

PENGEMIS : : Ampun, nona, ampun.

ANI : Ya, kalau sudah ketahuan, minta ampun.

PENGEMIS : Saya tak akan mencuri, kalau saya punya uang.

Dari kutipan dialog diatas, pengarang menggambarkan perilaku menyimpang dari seorang pengemis untuk mendapatkan uang. Dari sini dapat dilihat bahwa adanya keinginan-keinginan tersebut karena kebutuhan ekonomi yang tidak terpenuhi seperti sulit untuk mendapatkan makanan, pakaian, atau pun rumah untuk tempat tinggal.

\section{Agama dan Kepercayaan}

Agama adalah ajaran atau sistem yang mengatur tata keimanan (kepercayaan) kepada Tuhan Yang Mahakuasa, tata peribadatan, dan tata kaidah yang bertalian dengan pergaulan manusia dan manusia serta lingkungannya dengan kepercayaan itu (KBBI, 2008:17). Karakter tersebut memaparkan suatu watak yang selalu bergantung pada Sang Pencipta, berpegang, dan berpedoman teguh pada Tuhan semesta alam. Hal itu terbukti dalam kutipan berikut. "Sabar, Nak, sabar. Orang sabar akan dikasihani Tuhan ...”

Kutipan di atas menjelaskan perkataan paman Usman yang ditujukan kepada Ani agar selalu bersabar karena di dunia ini Ani hidup sendiri tanpa bapak dan ibu. Orang yang dianggapnya sebagai keluarga tidak sayang dan menganggapnya lagi. Usman menyuruh Ani untuk bersabar karena orang yang sabar akan memperoleh pertolongan Tuhan.

\section{Menceritakan Usaha Mencari Penghidupan}

Seperti yang diceritakan dalam isi drama tersebut bahwa tokoh Ani mencari kehidupannya dengan menjadi seorang pelayan rumah makan milik keluarga 
Sudarma. Tokoh Pengemis mencari kehidupannya dengan menjadi seorang yang meminta-minta belas kasihan orang lain. Sementara itu, Sudarma orang kaya mencari kehidupannya dengan memiliki rumah makan. Di sini pengarang menggambarkan bahwa dalam mencari sebuah kehidupan, seseorang memiliki kebebasan dalam memilihnya. Manusia dapat memilih jalan kehidupannya. Dalam drama tersebut seseorang yang menjadi orang kaya hendaknya tidak sombong dan semena-mena terhadap orang lain, terlebih orang miskin. Orang kaya juga harus sadar untuk menyisihkan sebagian hartanya untuk orang miskin karena sebagian harta yang dimiliki merupakan harta orang lain. Sebagai orang miskin atau digambarkan pengarang sebagai tokoh Pengemis, janganlah hanya menadahkan bantuan dari orang lain. Pengemis sebaiknya berusaha mencari penghidupan lebih baik.

\section{KESIMPULAN}

Naskah drama Bunga Rumah Makan karya Utuy Tatang Sontani ditulis pada tahun 1948. Naskah ini tergolong ke dalam drama realis. Drama realisme mencoba meyakinkan kepada penonton bahwa peristiwa yang dihadirkan di atas pentas adalah seolah-olah nyata. Drama realisme hendak 'menipu' mata penonton bahwa realitas diatas pentas adalah realitas kehidupan sehari-hari. Drama ini dikaji menggunakan teori sosiologi sastra yang hasilnya memiliki beberapa poin macam permasalahan dalam kehidupan sosial.

\section{DAFTAR PUSTAKA}

Anwar, F., \& Syam, A. (2018). Kritik Sosial dalam Naskah Drama Alangkah Lucunya Negeri Ini Karya Deddy Mizwar. Bahasa Dan Sastra, 3(3).

Bahtiar, A. (2017). Warna Lokal Betawi Dalam Kumpulan Cerpen Terang Bulan Terang Di Kali: Cerita Keliling Jakartakarya SM Ardan. In dalam Prosiding Seminar Sosiologi Sastra UI.

Hidayat, A. (2015). Unsur-unsur Intrinsik dan Nilai-nilai Psikologis Dalam Naskah Drama "Matahari Di Sebuah Jalan Kecil" Karya Arifin C Noor Sebagai Alternatif Pemilihan Bahan Ajar Sastra di SMA. Fon: Jurnal Pendidikan Bahasa Dan Sastra Indonesia, 5(2).

Hikmat, A., Solihati, N., \& Hidayatullah, S. (2016). Teori Sastra: Pengantar Kesusastraan Indonesia. Jakarta: Uhamka Press.

Ibrohim, I., Turahmat, T., \& Wardani, O. P. (2018). Perbedaan Alur Antara Naskah Drama Nenek Tercinta Karya Arifin C. Noer dan Pertunjukannya. Jurnal Pendidikan Bahasa Indonesia, 6(1), 1-9.

Lestari, A. K. (2020). Aspek Sosial dalam Novel Hujan Karya Tere Liye. Lingua Franca: Jurnal Bahasa, Sastra, Dan Pengajarannya, 4(1), 78-96.

Mulyaningsih, C. T. (2017). Kritik Sosial Dalam Naskah Drama Tik, Karangan Budi Yasin Misbach: Suatu Pendekatan Hermeneutik. AKSIS: Jurnal Pendidikan Bahasa Dan Sastra Indonesia, 1(2), 253-266.

Puspitasari, N. A., Hidayatullah, S., \& Jupri, R. (2019). Revitalisasi Sastra Lisan Melalui Pelatihan Media dan Waktu Mendongeng Bagi Orang Tua dan Guru PAUD / TK Aisyiah Di Jakarta Selatan. Abdinus, 2(2), 115-121.

Solihat, I. (2017). Konflik, Kritik Sosial, dan Pesan Moral dalam Naskah Drama Cermin Karya Nano Riantiarno (Kajian Sosiologi Sastra). Jurnal Membaca Bahasa Dan Sastra 
Indonesia, 2(1), 29-36.

Sugiyono. (2018). Metode Penelitian Kualitatif. (S. Y. Suryandari, Ed.) (2nd ed.). Bandung: Alfabeta.

Suprabowo, D., \& Wiradharma, G. (2018). Nasionalisme Utuy Tatang Sontani dalam Naskah

Drama Bunga Rumah Makan yang Bertema Roman Picisan: Hermeneutika Sastra.

Arkhais-Jurnal Ilmu Bahasa Dan Sastra Indonesia, 9(1), 23-34.

Suwondo, T. (2011). Studi Sastra: Konsep Dasar Teori dan Penerapannya pada Karya Sastra. Yogyakarta: Gama Media.

Syani, A. (2007). Sosiologi skematika, teori, dan terapan. Jakarta: Bumi Aksara.

Wellek, R., \& Warren, A. (1990). Teori Kesusastraan. Jakarta: Pustaka Jaya.

Zain, F. R. (2020). Penyimpangan Prinsip Kerja Sama dalam Naskah Drama Bunga Rumah

Makan Karya Utuy Tatang Sontani. Academica: Journal of Multidisciplinary Studies, 2(1), 71-82. 
Imajeri: Jurnal Pendidikan Bahasa dan Sastra Indonesia

Vol. 01, No. 1, pp. 1-11; September 2018

ISSN 2654-4199 